\title{
Análise de áreas verdes urbanas no município de Patos, Paraíba
}

\section{Camila Costa da Nóbrega ${ }^{1 *}$, Patrícia Carneiro Souto², Talytta Menezes Ramos², Luan Henrique Barbosa de Araújo $^{3}$, Edjane Oliveira de Lucena ${ }^{1}$, César Henrique Alves Borges ${ }^{3}$}

\begin{abstract}
RESUMO: O trabalho teve como objetivo avaliar as condições de áreas verdes na área central da cidade de Patos e gerar o percentual de cobertura vegetal. O estudo foi realizado nas Praças Edivaldo Motta, Alcides Carneiro e Getúlio Vargas. Os indivíduos arbóreos presentes em cada área foram avaliados quantitativamente (altura, diâmetro da copa e circunferência a altura do peito) e qualitativamente quanto aos aspectos físicos e sanitários. Na praça Edivaldo Motta foram identificados 31 indivíduos, distribuídos em oito espécies sendo aproximadamente $71 \%$ nativas. Na praça Alcides Carneiro 41 indivíduos arbóreos foram identificados, distribuídos em nove espécies, cerca de $76 \%$ dos indivíduos foram classificados como nativos. Na praça Getúlio Vargas foram identificados 24 indivíduos arbóreos, subdivididos em seis espécies, sendo aproximadamente $67 \%$ nativos. No geral, verificou-se que a maior parte dos indivíduos apresentaram bom aspecto físico e sanitário. Na praça Getúlio Vargas constatou-se maior percentual de cobertura vegetal $(86,48 \%)$. As três áreas estudadas apresentaram alta qualidade ambiental, com tendência à homogeneidade e em boas condições de conservação física e ambiental.
\end{abstract}

Palavras-chave: cobertura vegetal, espaços verdes, qualidade ambiental, silvicultura urbana.

\section{Analysis of urban green areas in the municipality of Patos, Paraíba}

\begin{abstract}
The objective of this study was to evaluate the conditions of the green areas in the central area of the Patos city and generate the percentage of vegetation cover of the areas. The study was performed at Edivaldo Motta, Alcides Carneiro and Getulio Vargas Squares. The individual trees in each area were evaluated quantitatively (height, diameter and circumference at breast height) and qualitatively regarding physical and health. Based on the data, we calculated the percentage of vegetation cover and realized the physical and qualitative analysis of the areas. In Edivaldo Motta square 31 individuals were identified, distributed among eight species being approximately $71 \%$ native. In Alcides Carneiro square 41 individual trees were identified, distributed in nine species, about $76 \%$ of individuals were classified as native. In Getulio Vargas square we identified 24 individual trees, subdivided into six species, of which approximately $67 \%$ were native. Overall, it was found that most of the individuals found in areas showed good physical appearance and health. In Getulio Vargas square we found a higher percentage of vegetation cover $(86.48 \%)$. The three areas studied showed a high environmental quality, with a tendency to homogeneity when in good physical and environmental conservation.
\end{abstract}

Keywords: vegetal cover, green spaces, environmental quality, urban forestry.

\section{INTRODUÇÃO}

Atualmente, as discussões que reúnem diversos membros de diferentes entidades de todo o mundo estão ligadas à questão ambiental, principalmente no meio urbano que vem sofrendo alterações ambientais devido à expansão das cidades com o aumento de áreas construídas, especialmente nas áreas centrais das cidades, pavimentação, aumento da frota de veículos, poluição do ar, poluição sonora e diminuição da cobertura vegetal urbana.

Áreas Verdes podem ser definidas como lugares de vegetação arbórea ou não, introduzidas ou presentes em meio urbano como praças, parques ou cemitérios, em geral com a finalidade de ornamentar esses locais, propiciar lazer e favorecer a qualidade de vida da população (LUZ et al., 2012; MACIEL, BARBOSA, 2015). A presença do verde nas praças públicas torna-se essencial, tanto pelo lado visual de embelezamento, como também por suas funções biológico-climáticas que desempenham, deixando o ambiente mais arejado (GOMES, SOARES, 2003).

A falta de planejamento, que considere os elementos da natureza, é um problema grave. Além do empobrecimento da paisagem urbana, são diversos os problemas que podem ocorrer, em virtude dos muitos subsistemas que existem nas cidades (LOBODA, DE ANGELIS, 2005). Projetos

\footnotetext{
Recebido em 07/04/2018; Aceito para publicação em 27/09/2018

${ }^{1}$ Universidade Federal da Paraíba

${ }^{2}$ Universidade Federal de Campina Grande

${ }^{3}$ Universidade Federal Rural de Pernambuco

*E-mail: camila_cnobrega@hotmail.com
} 
urbanísticos inadequados, falta de manutenção dos espaços públicos, atos de vandalismo e outros processos sociais envolvidos não são compatíveis e favoráveis ao cumprimento das reais funções das áreas verdes urbanas (GOMES, MARTIN, 2017).

Borges et al. (2010) afirmam que os problemas urbanos têm impacto direto no dia-a-dia da população, interferindo no estado de ânimo das pessoas, podendo ocasionar diversos problemas à saúde como doenças respiratórias, cardiovasculares e até psíquicas. Assim, as áreas verdes contribuem de forma direta, para o bem-estar humano, pois causam melhor sensação térmica e bem-estar psicológico, além de reduzirem o impacto da chuva e diminuírem a poluição atmosférica causada pelos diversos meios de transportes, pelas indústrias e outros serviços. Entendendo melhor a motivação para o uso das áreas verdes urbanas, Marques et al. (2014) salientam que é possível realizar planejamento e manutenção destas áreas segundo as necessidades reais da população. A existência de espaços verdes causa um efeito minimizador sobre o clima do meio, sendo percebido através da luminosidade, umidade, temperatura, radiação solar, ventilação, poluição e nível de ruído (ALVAREZ, 2004; BARROS et al., 2017).

Dessa forma, avaliar as condições em que se encontram as áreas verdes e sua distribuição na área urbana, permite um diagnóstico mais aprofundado, que pode direcionar futuros projetos de urbanização e sensibilizam os gestores sobre a importância de alocação de áreas verdes maiores e melhores estruturadas, as quais proporcionam lazer, estética e melhor qualidade ambiental para a população. Portanto, o objetivo desse trabalho foi avaliar as condições de áreas verdes na área central da cidade de Patos, PB e gerar o percentual de cobertura vegetal das áreas.

\section{MATERIAL E MÉTODOS}

O estudo foi desenvolvido na cidade de Patos, localizada na mesorregião Sertão Paraibano, cuja área territorial do município é de $512,79 \mathrm{~km}^{2}$ e a zona urbana com $5,11 \mathrm{~km}^{2}$. Segundo dados do IBGE (2018), a população do município em 2010 era de 100.674 habitantes e estimada no ano de 2017 em 107.790 habitantes. O clima é do tipo BSh segundo a classificação de Köppen (1996), quente e seco, com temperatura máxima de $38^{\circ} \mathrm{C}$ e mínima de $28^{\circ} \mathrm{C}$. A vegetação no entorno do município é caatinga hiperxerófila, já bastante devastada.

Inicialmente foi feita a pesquisa junto à Secretaria de Infraestrutura da Prefeitura Municipal de Patos para obter informações sobre as áreas verdes inter-relacionadas no ambiente urbano. De acordo com a supracitada Secretaria, a cidade de Patos possui 23 praças e um parque municipal.

O critério de escolha das áreas de amostragem foi realizar o levantamento das áreas verdes mais representativas, localizadas na parte central da cidade. Seguindo a metodologia adotada por Jesus, Braga (2005) foi feita a sistematização de categorias de espaços livres (Tabela 1).

Tabela 1. Sistematização de categorias de espaços livres na cidade de Patos, PB

\begin{tabular}{|c|c|c|c|c|c|c|}
\hline Nome & Categoria & Área $\left(\mathrm{m}^{2}\right)$ & Situação & Função & Coordenadas & Altitude \\
\hline Praça Edivaldo Motta & Praça & $3.699,51$ & Público & Lazer & $07^{\circ} 01^{\prime} 48,72^{\prime \prime}$ S 37º'39.27” O & $250 \mathrm{~m}$ \\
\hline Praça Getúlio Vargas & Praça & $3.631,53$ & Público & Lazer & $07^{\circ} 01 ' 27,70^{\prime \prime} \mathrm{S} 37^{\circ} 16^{\prime} 32.81^{\prime \prime} \mathrm{O}$ & $245 \mathrm{~m}$ \\
\hline Praça Alcides Carneiro & Praça & $2.881,69$ & Público & Lazer & $07^{\circ} 01^{\prime} 04.72^{\prime \prime}$ S $37^{\circ} 16^{\prime} 59.88^{\prime \prime} \mathrm{O}$ & $253 \mathrm{~m}$ \\
\hline
\end{tabular}

$\mathrm{Na}$ coleta de dados foram avaliados e identificados os indivíduos arbóreos presentes em cada área selecionada para o estudo. Para o registro e coleta de dados de trabalho de campo foram utilizadas planilhas, trena, fita métrica, câmera digital e baliza de 2,0 metros. A identificação das espécies arbóreas foi realizada no momento da coleta de dados. Em caso de dúvidas, foi coletado um ramo florido para posterior identificação no herbário da UFCG, Campus de Patos-PB, através de exsicatas e literatura especializada, sendo a nomenclatura da espécie atualizada seguindo Angiosperm Phylogeny Group (APG III).

Para a avaliação quantitativa e qualitativa dos indivíduos arbóreos, inicialmente foi realizada a contagem e identificação dos indivíduos presentes em cada área verde pesquisada. Em seguida, foi medida a circunferência na altura do peito (CAP) utilizando uma fita métrica e a altura total das árvores $(\mathrm{H})$ com a baliza.

O diâmetro de copa (DC) foi determinado através de duas medições, sendo uma no sentido norte-sul e outra no sentido leste-oeste, conforme metodologia utilizada por Harder et al. (2006) e que, segundo os autores, essa forma de medição é para verificar a uniformidade da copa quanto ao seu desenvolvimento e levantar o índice de cobertura arbórea.

Quanto à origem, as espécies foram classificadas em nativas, subespontâneas e exóticas em relação à Flora Brasileira, independente do bioma.

Quanto aos aspectos físicos e sanitários, os indivíduos presentes nas áreas verdes foram classificados, segundo adaptação de Silva (2012), em estado bom (indivíduo vigoroso e sadio, sem sinais de ataque de "pragas", doenças ou injúrias 
mecânicas), satisfatório (indivíduo com algum sinal de deficiência superficial, ataque de "pragas", doenças, ou injúria mecânica superficial), ruim (indivíduo em estado avançado de declínio, com ataque ou dano intenso de "pragas" ou doenças, resultando em risco de queda) e morto.

Em relação ao porte, os indivíduos foram classificados de acordo com a altura em pequeno (até 4 metros), médio (de 4 a 7 metros) e grande (maior que 7 metros), conforme Alencar (2014).

Em cada área verde foi calculado o percentual de cobertura vegetal (PCV) em função da superfície total da área. Para isso foi medido com GPS a área total $\left(\mathrm{m}^{2}\right)$ e a área explorada pela copa das árvores $\left(\mathrm{m}^{2}\right)$, obtida pelo somatório da área de todas as copas existentes na praça.

O percentual de cobertura vegetal das áreas foi calculado a partir do somatório das áreas das copas das árvores de cada área verde dividido pela área total avaliada, multiplicado por cem (Equação 1), conforme proposto por Abreu et al. (2012):

$$
P C V a=\frac{\text { Eárea de cobertura vegetal }}{\text { àrea total avaliada }} \times 100 \text { (Equação 1) }
$$

Os dados obtidos foram organizados em planilhas e, posteriormente, cada área verde foi analisada e caracterizada segundo as espécies encontradas, sendo também calculado o percentual de cobertura para cada área.

Baseado no percentual de cobertura vegetal proporcionada pelas árvores, as praças foram classificadas quanto a sua qualidade ambiental em baixaaté $5,0 \%$ de cobertura vegetal), média (10,0 a $25,0 \%$ ) e alta (acima de 30,0\%), conforme Borges et al. (2010).

\section{RESULTADOS E DISCUSSÃO}

\section{Praça Edivaldo Motta}

No levantamento de campo da Praça Edivaldo Motta, foram identificados 31 indivíduos, distribuídos em oito espécies, conforme apresentado na tabela 2.

Das oito espécies presentes, quatro são nativas do Brasil (Ziziphus joazeiro, Tabebuia aurea, Anadenanthera colubrina e Crateva tapia), sendo as mais abundantes o Ziziphus joazeiro com 13 indivíduos e Tabebuia aurea com oito indivíduos, com altura média de $5,76 \mathrm{~m}$ e $8,38 \mathrm{~m}$, respectivamente.

Tabela 2. Avaliação dendrométrica das espécies arbóreas na Praça Edivaldo Motta

\begin{tabular}{|c|c|c|c|c|c|c|}
\hline Espécie & Nome Científico & Origem & $\begin{array}{l}\mathrm{N}^{0} \text { de } \\
\text { Ind. }\end{array}$ & $\mathbf{C A P}^{*}(\mathbf{m})$ & $\mathrm{DC}(\mathbf{m})$ & $\mathbf{H}(\mathbf{m})$ \\
\hline Juazeiro & Ziziphus joazeiro Mart. & Nativa & 13 & $1,26-0,37 * *$ & $12,10-5,55$ & $8,00-4,50$ \\
\hline Craibeira & $\begin{array}{l}\text { Tabebuia aurea (Silva Manso) Benth. \& } \\
\text { Hook. f. ex S. Moore }\end{array}$ & Nativa & 8 & $1,25-0,13$ & $11,00-2,00$ & $15,00-2,00$ \\
\hline Mata fome & Pithecellobium dulce (Roxb.) Benth. & Subespontânea & 4 & $1,36-0,71$ & $11,65-5,90$ & $8,00-6,50$ \\
\hline $\begin{array}{l}\text { Flamboyant } \\
\text { Mirim }\end{array}$ & Caesalpinia pulcherrima & Subespontânea & 2 & $0,18-0,17$ & $4,65-3,00$ & $4,00-2,50$ \\
\hline Cássia amarela & Senna siamea (Lam.) H. S. Irwin \& Barneby & Exótica & 1 & 0,84 & 7,25 & 7,00 \\
\hline Flamboyant & Delonix regia (Bojer ex Hook) Raf. & Subespontânea & 1 & 0,18 & 2,75 & 3,50 \\
\hline Trapiá & Crateva tapia $\mathrm{L}$. & Nativa & 1 & 1,03 & 3,00 & 3,50 \\
\hline Nim indiano & Azadirachta indica & Exótica & 1 & 0,31 & 5,05 & 4,00 \\
\hline Total & & & 31 & & & \\
\hline
\end{tabular}

*CAP- Circunferência à Altura do Peito; DC- Diâmetro da Copa; H- Altura.

**Maior e menor valor do indivíduo encontrado.

As espécies Pithecellobium dulce e Caesalpinia pulcherrima são de origem subespontânea com domínios fitogeográficos em outros biomas do Brasil, e por isso são consideradas naturalizadas. A espécie Ziziphus joazeiro, apesar do porte médio, tem copa densa e folhas perenes, que proporcionam sombra o ano inteiro na praça, ajudando para que as principais funções de sombreamento e diminuição da temperatura ocorram durante todo o ano na área verde em questão (IGANCI, 2012; LEWIS, 2011).

A diversidade de espécies permite a cada uma desempenhar diferentes papéis no setor urbano
(ALENCAR, 2014). Assim, as espécies identificadas desempenham diferentes funções que ajudam na melhoria da qualidade ambiental da cidade, seja pela retenção de partículas, sombreamento, minimização da temperatura e proporcionar um ambiente visualmente mais atrativo.

Verifica-se na figura 1 que a maior parte das espécies utilizadas na arborização da praça são de origem nativa $(70,97 \%), 22,58 \%$ são de origem subespontânea e apenas 6,45\% são exóticas, ou seja, espécies oriundas de outros países que foram 
introduzidas na arborização urbana das cidades brasileiras.

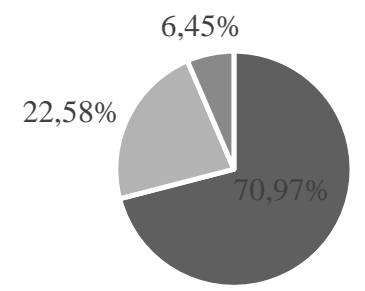

- Nativas - Subespontâneas " Exóticas

Figura 1. Distribuição percentual de Indivíduos arbóreos, por origem, presentes na Praça Edivaldo Motta

É provável que a maior abundância de espécies nativas nesta área verde seja devido ao espaço disponível para o desenvolvimento dos indivíduos que apresentam copa bem desenvolvida, proporcionam sombra e melhoram o microclima local, além de serem mais adaptadas ao clima e ao solo da região.

Machado et al. (2006), em estudo realizado na cidade de Teresina (PI), concluíram que a participação das árvores na arborização urbana da cidade foi considerada boa, pois os resultados demonstraram que a vegetação presente na arborização não se concentra apenas nos parques ambientais, mas tem significativa participação na arborização geral da cidade.

Em relação aos aspectos físicos e sanitários (Tabela 3), as espécies ocorrentes foram classificadas em estado bom $(75,0 \%)$, seguido por satisfatório $(12,5 \%)$ e ruim $(12,5 \%)$. Verificou-se que, das espécies identificadas, quatro foram classificadas como de pequeno porte, contribuindo com $23,0 \%$ do total de indivíduos, e as de médio e grande porte contribuíram com $45,0 \%$ e $32,0 \%$, respectivamente, distribuídos em apenas duas espécies para cada porte.

Tabela 3. Caracterização vegetativa das espécies da Praça Edivaldo Motta

\begin{tabular}{ccc}
\hline Espécie & Aspectos Físicos e Sanitários & Porte \\
\hline Ziziphus joazeiro & Satisfatório & Médio \\
Tabebuia aurea & Bom & Grande \\
Pithecellobium dulce & Bom & Grande \\
Caesalpinia pulcherrima & Bom & Pequeno \\
Senna siamea & Bom & Médio \\
Delonix regia & Bom & Pequeno \\
Crateva tapia & Ruim & Pequeno \\
Azadirachta indica & Bom & Pequeno \\
\hline
\end{tabular}

Pequeno: até 4 metros de altura; Médio: de 4 a 7 metros de altura; Grande: maior que 7 metros de altura.

As árvores com bom aspecto indicam boa conservação e boas condições da parte aérea. Já as árvores que se encontraram com estado satisfatório são aquelas que, apesar de apresentarem pequenas injúrias mecânicas como cortes na casca e presença de pregos, apresentaram um bom aspecto visual.

As injúrias observadas em algumas espécies foram devido à presença de pregos aderidos de forma inadequada no tronco, utilizados para fixação da iluminação da praça na época do Natal. As classificadas com aspecto ruim foram aquelas que apresentavam podas drásticas, fato observado na Crateva tapia que foi submetida a uma poda drástica modificando totalmente a simetria de sua copa.

Redin et al. (2010), avaliando a fitossanidade de praças de Cachoeira do Sul (RS), identificaram indivíduos que sofreram injurias de vários tipos, com cortes nos troncos das árvores, objetos aderidos como pregos, correntes de ferro, entre outros, inferindo ações de vândalos.

Salienta-se a importância da manutenção das praças, com a realização de podas, evitando que as árvores tenham um crescimento desordenado, podendo afetar a rede elétrica, fios de telefone, etc. Lima Neto et al. (2007) afirmaram que as podas preventivas têm por característica a prevenção de acidentes. No entanto, em estudo na cidade de Aracaju (SE), constataram que nas áreas analisadas as podas não são realizadas com tanta eficácia, o que pode causar prejuízos tanto para a árvore como para as pessoas que frequentam os espaços.

\section{Praça Alcides Carneiro}

$\mathrm{Na}$ Praça Alcides Carneiro foram identificados 41 indivíduos arbóreos, distribuídos em nove espécies (Tabela 4). 


\begin{tabular}{|c|c|c|c|c|c|c|}
\hline Espécie & Nome Científico & Origem & $N^{0}$ de Ind. & CAP* (m) & DC (m) & $\mathbf{H}(\mathbf{m})$ \\
\hline Nim indiano & Azadirachta indica & Exótica & 22 & $0,90-0,11 * *$ & $7,10-1,15$ & $8,00-2,50$ \\
\hline Craibeira & $\begin{array}{l}\text { Tabebuia aurea (Silva Manso) } \\
\text { Benth. \& Hook.f. ex S. Moore }\end{array}$ & Nativa & 8 & $1,43-0,67$ & $13,75-7,65$ & $16,00-10,00$ \\
\hline Tamarindo & Tamarindus indica $\mathrm{L}$ & Exótica & 3 & $0,70-0,54$ & $8,50-6,65$ & $7,00-5,00$ \\
\hline Cola & Cordia myxa L. & Exótica & 3 & $0,72-0,46$ & $8,20-6,95$ & $7,00-3,50$ \\
\hline Cássia amarela & Senna siamea $\mathrm{L}$. & Exótica & 1 & 0,795 & 11,5 & 9 \\
\hline Esponjinha & Albizia lebbeck & Exótica & 1 & 0,76 & 10,05 & 9 \\
\hline Mata fome & Pithecellobium dulce (Roxb.) Benth. & Subespontânea & 1 & 1,2 & 10,95 & 8 \\
\hline Flamboyant Mirim & Caesalpinia pulcherrima & Subespontânea & 1 & 0,25 & 3,75 & 5 \\
\hline Oliveira & Olea europaea $\mathrm{L}$. & Exótica & 1 & 0,445 & 8,2 & 8 \\
\hline
\end{tabular}

CAP: Circunferência à Altura do Peito; DC: Diâmetro da Copa; H: Altura.

**Maior e menor valor do indivíduo encontrado.

A alta representatividade da espécie Azadirachta indica na praça (mais de $50 \%$ dos indivíduos arbóreos) pode ocasionar sérios problemas pela grande quantidade. Justifica-se o seu plantio pelo seu rápido crescimento para proporcionar sombra aos táxis da praça, além de serem facilmente moldáveis através da poda.

A alta concentração de uma mesma espécie é um problema frequente na composição da arborização de praças, parques e ruas, aumentando o risco de doenças e pragas que poderão levar a morte uma parcela significativa dos indivíduos que compõe a arborização. A medida para corrigir esse problema é diminuir o plantio de uma única espécie e, consequentemente diversificar o número de espécies (LIMA NETO; SOUZA, 2009).

A figura 2 apresenta a distribuição das espécies quanto à origem, onde os indivíduos arbóreos exóticos representam $75,61 \%$, com destaque para a espécie Azadirachta indica com $53,65 \%$ em relação ao total.

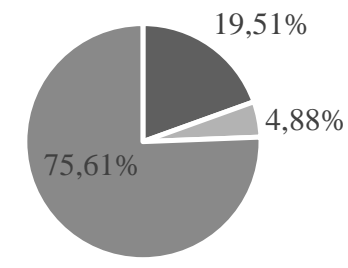

- Nativas " Subespontâneas - Exóticas

Figura 2. Distribuição percentual de indivíduos arbóreos, por origem, presentes na Praça Alcides Carneiro

Em estudo realizado por Alencar (2014) na cidade São João do Rio do Peixe (PB), cerca de 50\% da arborização da cidade é composta pela espécie Azadirachta indica. As espécies de origem subespontâneas (Pithecellobium dulce e Caesalpinia pulcherrima) contribuíram com $4,88 \%$ do total. Como representante da flora nativa foi registrado apenas a ocorrência da Tabebuia aurea contribuindo com $19,51 \%$ dos indivíduos inventariados.

Kramer, Krupek (2012), obtiveram resultados semelhantes ao realizar o levantamento florístico e avaliar algumas características ecológicas das principais praças públicas do Município de Guarapuava (PR), onde 40,2\% eram representantes da flora nativa nacional, enquanto $59,8 \%$ de indivíduos de origem exótica. Segundo os autores, as espécies de origem exótica vêm sendo cada vez mais utilizadas pelo seu potencial paisagístico e facilidade de cultivo e manejo.

É importante salientar que a introdução de espécies de diferentes origens é importante para o desenvolvimento sustentável urbano de modo que cada espécie venha a desempenhar diferentes funções, proporcionando assim uma melhor qualidade de vida da população que usufrui dessa área.

Quanto ao aspecto físico e sanitário das espécies presentes nessa praça, observa-se na tabela 5 que todos os indivíduos foram classificados com bom aspecto $(100,0 \%)$, indicando boa conservação das espécies. Em relação ao porte, aproximadamente $44,0 \%$ dos indivíduos foram classificados como pequeno, médio porte com $24,0 \%$ e os $32,0 \%$ restante se enquadraram na categoria de grande porte. 
Tabela 5. Caracterização vegetativa das espécies da Praça Alcides Carneiro

\begin{tabular}{ccc}
\hline Espécie & Aspectos Físicos e Sanitários & Porte (\%) \\
\hline Azadirachta indica & Bom & Pequeno \\
Tabebuia aurea & Bom & Grande \\
Tamarindus indica & Bom & Médio \\
Cordia myxa & Bom & Médio \\
Senna siamea & Bom & Grande \\
Albizia lebbeck & Bom & Grande \\
Pithecellobium dulce & Bom & Grande \\
Caesalpinia pulcherrima & Bom & Médio \\
Olea europaea & Bom & Grande
\end{tabular}

Pequeno: até 4 metros de altura; Médio: de 4 a 7 metros de altura; Grande: maior que 7 metros de altura.

Em estudo semelhante, Schallenberger et al. (2010) avaliaram as condições gerais das árvores de praças e parques da cidade de Irati (PR), e observaram que aproximadamente 55\% das árvores foram classificadas quanto ao aspecto como excelentes e boas. Os autores afirmam que esses indivíduos não necessitam de interferências visando melhorias, assim como na Praça Alcides Carneiro, pois os indivíduos dessa praça se encontram em boas condições, necessitando apenas de manutenção.

\section{Praça Getúlio Vargas}

Na Praça Getúlio Vargas foram identificados 24 indivíduos arbóreos, distribuídos em seis espécies (Tabela 6).

Tabela 6. Avaliação dendrométrica das espécies arbóreas na Praça Getúlio Vargas

\begin{tabular}{|c|c|c|c|c|c|c|}
\hline Espécie & Nome Científico & Origem & $\mathrm{N}^{\mathrm{o}}$ de Ind. & CAP* (m) & DC (m) & $\mathbf{H}(\mathbf{m})$ \\
\hline Craibeira & $\begin{array}{l}\text { Tabebuia aurea (Silva Manso) } \\
\text { Benth. \& Hook. f. ex S. Moore }\end{array}$ & Nativa & 13 & $0,73-2,56 * *$ & $7,55-22,15$ & $8,00-30,00$ \\
\hline Cássia amarela & Senna siamea $\mathrm{L}$. & Exótica & 6 & $0,43-1,02$ & $5,85-10,00$ & $4,50-9,00$ \\
\hline Mata fome & Pithecellobium dulce (Roxb.) Benth. & Nativa & 2 & $0,23-0,86$ & $9,30-10,80$ & $6,00-10,00$ \\
\hline Nim indiano & Azadirachta indica & Exótica & 1 & 0,60 & 6,65 & 10,00 \\
\hline Flamboyant & Delonix regia (Bojer ex Hook) Raf. & Subespontânea & 1 & 1,41 & 16,10 & 12,00 \\
\hline Pitombeira & Talisia esculenta (Cambess.) Radlk. & Nativa & 1 & 0,50 & 8,40 & 7,00 \\
\hline Total & & & 24 & & & \\
\hline
\end{tabular}

CAP: Circunferência à Altura do Peito; DC: Diâmetro da Copa; H: Altura.

**Maior e menor valor de indivíduos encontrados.

Apesar da pequena quantidade de indivíduos presentes na praça, a maioria é da espécie Tabebuia aurea, com $54,16 \%$ do total inventariado. Os indivíduos apresentam diâmetro da copa e porte grandes, proporcionando grande extensão de sombra para a praça, melhorando a qualidade do ar, o conforto térmico e estético. Salienta-se que nem sempre um número menor de indivíduos é sinônimo de menor cobertura vegetal. Porém, a escolha de espécies com copa mais densa e de boa estrutura pode resultar em maior eficiência da arborização.
Quanto à origem das espécies, $66,67 \%$ dos indivíduos são nativas do Brasil, sendo que do total de nativas, a espécie Tabebuia aurea contribui com $81,25 \%$ dos indivíduos (Figura 3). É importante utilizar espécies nativas para a arborização urbana, considerando os aspectos ecológico adaptativo e funcional, principalmente da região em estudo. As espécies nativas são recomendadas para garantir a conservação do material genético da espécie e as relações ecológicas de dispersão de propágulos envolvendo a interação entre a fauna e flora dentro do ambiente urbano (PAIVA et al., 2010). 


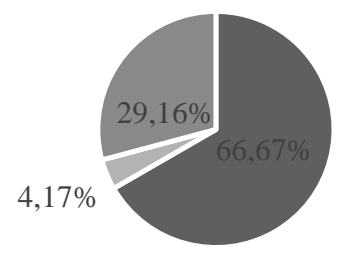

- Nativas - Subespontâneas - Exóticas

Figura 3. Distribuição percentual de Indivíduos arbóreos, por origem, presentes na Praça Getúlio Vargas

Defendem, portanto, aumentar, a diversidade das espécies no ambiente urbano, principalmente, de espécies nativas, buscando nelas as funções que tragam benefícios ao meio ambiente, proporcionando melhor qualidade de vida para a população que irá usufruir de seus serviços ambientais (PAIVA et al., 2010).

Os aspectos físicos e sanitários das espécies presentes na praça Getúlio Vargas foram considerados satisfatórios em relação ao crescimento e desenvolvimento dos indivíduos (Tabela 7).

Tabela 7. Caracterização vegetativa das espécies da Praça Getúlio Vargas

\begin{tabular}{ccc}
\hline Espécie & Aspectos Físicos e Sanitários & Porte $(\%)$ \\
\hline Tabebuia aurea & Satisfatório & Grande \\
Senna siamea & Satisfatório & Médio \\
Pithecellobium dulce & Satisfatório & Grande \\
Azadirachta indica & Satisfatório & Grande \\
Delonix regia & Satisfatório & Grande \\
Talisia esculenta & Satisfatório & Médio \\
\hline
\end{tabular}

Pequeno: até 4 metros de altura; Médio: de 4 a 7 metros de altura; Grande: maior que 7 metros de altura.

Observaram-se várias injúrias provocadas por pregos que, provavelmente, eram utilizados para fixação de enfeites das festividades juninas e natalinas, o que pode colocar em risco a longevidade das árvores, pois dependendo da profundidade, eles podem estar afetando a passagem do floema e de alguns nutrientes que a planta necessita para sobreviver.

Schallenberger et al. (2010), observaram que $45 \%$ dos indivíduos estudados, apresentaram condições regulares, ruins e péssimas, necessitando de tratos culturais, podas, controle de pragas e doenças e em alguns casos há a necessidade de serem substituídas.

Quanto ao porte (Tabela 7), a maioria das espécies apresentavam indivíduos de grande porte
(75,0\%), exceto as espécies Senna siamea e Talisia esculenta que foram classificadas como médio porte, correspondendo a $25,0 \%$ dos indivíduos. A presença de indivíduos de grande porte, tal como Tabebuia aurea, provavelmente, é devido ao tempo de existência dessa área verde, uma das mais antigas da cidade de Patos.

Percentual de Cobertura das Áreas Verdes Avaliadas

O percentual de cobertura vegetal (PCV) de cada praça está disposto na Tabela 8. Constatou-se no presente estudo que todas as praças apresentaram alta qualidade ambiental, de acordo com a classificação utilizada por Borges et al. (2010).

Tabela 8. Percentual de Cobertura Vegetal das áreas verdes na cidade de Patos

\begin{tabular}{cccc}
\hline Tabela 8. Percentual de Cobertura Vegetal das áreas verdes na cidade de Patos & \\
\hline Área Verde & $\sum$ área da copa $\left.\mathbf{( m}^{\mathbf{2}}\right)$ & Área total $\left(\mathbf{m}^{\mathbf{2}}\right)$ & \% Cobertura \\
\hline Praça Edivaldo Motta & $2.006,48$ & $3.699,51$ & 54,24 \\
Praça Alcides Carneiro & $1.688,67$ & $2.881,69$ & 58,60 \\
Praça Getúlio Vargas & $3.140,57$ & $3.631,53$ & 86,48 \\
\hline
\end{tabular}

Baseando-se na classificação de Borges et al. (2010), as três praças são consideradas de alta qualidade ambiental, por apresentar percentual de cobertura vegetal maior que $30 \%$, com destaque para praça Getúlio Vargas que atingiu $86,48 \%$ de cobertura. Devido a isso, a percentagem de cobertura vegetal da praça Getúlio Vargas deve ser adotada como padrão para as demais praças da cidade e outras circunvizinhas. Verificou-se uma melhor sensação térmica, já que as características climáticas 
da região, com alta radiação solar e alta temperatura média anual, exigem mais áreas agradáveis proporcionadas pela vegetação, favorecendo a qualidade de vida da população.

A existência de espaços verdes nas cidades é um importante fator não só do ponto de vista estético, mas também para a sustentabilidade urbana, contribuindo para a amenização da temperatura, diminuição do ruído, filtração da água e para o meio ambiente urbano em geral (MUACUVEIA; FERREIRA, 2017).

\section{CONCLUSÕES}

1. As praças apresentaram tendência à homogeneidade devido à predominância de uma espécie.

2. A diversidade das espécies nas áreas verdes avaliadas deve ser aumentada, principalmente com a implantação de espécies nativas.

3. As três praças avaliadas apresentaram alta qualidade ambiental, com destaque para a praça Getúlio Vargas.

\section{REFERÊNCIAS}

ABREU, E. L.; MOURA, H. F. N.; LOPES, D. S.; BRITO, J. S. Análise dos índices de cobertura vegetal arbórea e sub-arbórea das praças do centro de TeresinaPI. In: Congresso Brasileiro de Gestão Ambiental, 3., 2012, Goiânia. Anais ... Goiânia: Ibeas - Instituto Brasileiro de Estudos Ambientais, 2012. p.1-11.

ALENCAR, L. S.; SOUTO, P. C.; MOREIRA, F. T. A.; SOUTO, J. S.; BORGES, C. H. A. Inventário qualiquantitativo da arborização urbana em São João do Rio do Peixe - PB. Agropecuária Científica no Semiárido, Patos, v.10, n.2, p.117-124, 2014.

ALVAREZ, I. A. Qualidade do espaço verde urbano: uma proposta de índice de avaliação. 2004. 187 f. Tese (Doutorado em Agronomia) - Escola Superior de Agricultura "Luiz de Queiroz". Universidade de São Paulo, São Paulo.

BARROS, A. P. S.; AZEVEDO, A. C. J.; DIAS, E. R. S.; OLIVEIRA, H. M. P. Planejamento urbano, áreas verdes e qualidade de vida: Uma análise comparativa entre os bairros Terra Firme e Cidade Velha - Belém/PA. Revista Eletrônica Geoaraguaia, Barra do Garças, v.7, n.2, p.6885,2017

BORGES, C. A. R. F.; MARIM, G. C.; RODRIGUES, J. E. C. Análise da cobertura vegetal como indicador de qualidade ambiental em áreas urbanas: um estudo de caso do bairro da Pedreira - Belém/PA. In: Seminário Latino Americano de Geografia Física, 6., 2010, Coimbra. ACTAS. Coimbra: Universidade de Coimbra, 2010. p.1 13.
GOMES, M. A. S.; SOARES, B. R. A vegetação nos centros urbanos: considerações sobre os espaços verdes em cidades médias brasileiras. Estudos Geográficos, Rio Claro, v.1, n.1, p.19-29, 2003

GOMES, M. R.; MARTIN, E. S. Degradação das praças públicas e os fatores de riscos para a população: Exemplos para a cidade de Natal/RN. GEOgraphia, Niterói, v.19, n.4, p.107-122, 2017

HARDER, I. C. F.; RIBEIRO, R. C. S.; TAVARES, A. R. Índices de área verde e cobertura vegetal para as praças do município de Vinhedo, SP. Revista Árvore, Viçosa, v.30, n.2, p.277-282, 2006

Instituto Brasileiro de Geografia e Estatística (IBGE). Cidades. Paraíba. Patos. 2018. Disponível em: <https://cidades.ibge.gov.br/brasil/pb/patos/panorama〉. Acesso em: 01 de mar. 2018.

IGANCI, J. R. V. Pithecellobium in Lista de Espécies da Flora do Brasil. Jardim Botânico do Rio de Janeiro. $2015 . \quad$ Disponível em: <http://floradobrasil.jbrj.gov.br/jabot/floradobrasil/FB836 09>. Acesso em 05 de mar. 2018.

JESUS, S. C.; BRAGA, R. Análise espacial das áreas verdes urbanas da estância de águas de São Pedro - SP. Caminhos Da Geografia, Uberlândia, v.18, n.16, p.207224, 2005

KOPPEN, W. Climatologia. Com un studio de los climas de la tierra. Fundo de Cultura Econômica: Buenos Aires, Fundo de Cultura Econômica, 1948, 31p. Trad. CORREIA, A.C.B. Sistemas Geográficos dos Climas. Recife: UFPE, 1996, 13p.

KRAMER, J. A.; KRUPEK, R. A. Caracterização florística e ecológica da arborização de praças públicas do município de Guarapuava, PR. Revista Árvore, Viçosa, v.36, n.4, p.647-658, 2012

LEWIS, G. P. Caesalpinia in Lista de Espécies da Flora do Brasil. Jardim Botânico do Rio de Janeiro. 2015. Disponível em: <http://floradobrasil.jbrj.gov.br/jabot/floradobrasil/FB228 44>. Acesso em 05 de mar. 2018.

LIMA NETO, E. M.; RESENDE, W. X.; SENA, M. G. D.; SOUZA, R. M. Análise das áreas verdes das praças do bairro centro e principais avenidas da cidade de AracajuSE. Revista Da Sociedade Brasileira De Arborização Urbana, Piracicaba, v.2, n.1, p.17-33, 2007

LIMA NETO, E. M.; SOUZA, R. M. Índices de densidade e sombreamento arbóreo em áreas verdes públicas de Aracaju, Sergipe. Revista da Sociedade Brasileira de Arborização Urbana, Piracicaba, v.4, n.4, p.47-62, 2009 
LOBODA, C. R.; DE ANGELIS, B. L. D. Áreas verdes públicas urbanas: conceitos, usos e funções. Revista Ambiência, Guarapuava, v.1 n.1, p. 125-139, 2005

LUZ, L. M.; ARRAES, R. R. M.; OLIVEIRA, S. R. Educação ambiental em áreas verdes urbanas como recurso didático para o ensino de biogeografia. Revista Geonorte, Manaus, v.3, n.4, p.171-177, 2012

MACIEL, T. T.; BARBOSA, B. C. Áreas verdes urbanas: história, conceitos e importância ecológica. CES Revista, Juiz de Fora, v.29, n.1. p.30-42, 2015

MACHADO, R. R. B. MEUNIER, I. M. J.; SILVA, J. A. A.; CASTRO, A. A. J. F. Árvores nativas para a arborização de Teresina, Piauí. Revista da Sociedade Brasileira de Arborização Urbana, Piracicaba, v.1, n.1, p.10-18, 2006

MUACUVEIA, R. R. M.; FERREIRA, W. R. Especificação das áreas verdes urbanas de uso público na zona central da cidade de Nampula-Moçambique. Periódico Técnico e Científico Cidades Verdes, Tupã, v.5, n.11, p.104-122, 2017

MARQUES, V. R.; SILVA, L. F.; SANTOS, G. R. B.; GAMARRA, N. L. R. Uso de áreas verdes em Mogi Mirim: Preferência da população. Revista da Sociedade
Brasileira de Arborização Urbana, Piracicaba, v.9, n.4, p.46-59, 2014

PAIVA, A. V.; LIMA, A. B. M.; CARVALHO, A.; M. JÚNIOR, A.; GOMES, A. et al. Inventário e diagnóstico da arborização urbana viária de Rio Branco, AC. Revista da Sociedade Brasileira de Arborização Urbana, Piracicaba, v.5, n.1, p.144-159, 2010

REDIN, C. G. VOGEL, C.; TROJAHN, C. D. P.; GRACIOLI, C. R.; LONGHI, S. J. Análise da arborização urbana em cinco praças do município de Cachoeira do Sul, RS. Revista da Sociedade Brasileira de Arborização Urbana, v.5, n.3, p.149-164, 2010

SCHALLENBERGER, L. S.; ARAÚJO, A. J.; ARAÚJO, M. N.; DEINER, J.; MACHADO, G. O. Avaliação da condição de árvores urbanas nos principais parques e praças do município de Irati-PR. Revista da Sociedade Brasileira de Arborização Urbana, Piracicaba, v.5, n.2, p.105-123, 2010

SILVA, R.N. Caracterização e análise quali-quantitativa da arborização em praças da área central da cidade de Arapiraca, AL. Revista da Sociedade Brasileira de Arborização Urbana, Piracicaba, v.7, n.2, p.102-115, 2012. 